\title{
UN MANIFIESTO NARRATIVO
}

\section{Antonio Muñoz Molina}

En este ensayo sobre los escritores como lectores, o sobre el aprendizaje del oficio de escritor mediante la lectura, Antonio Muñoz Molina se refiere a los importantes descubrimientos a los que lo llevó tempranamente su lectura de La orgía perpetua, de Mario Vargas Llosa. Advierte que probablemente ningún otro novelista ha hecho de tal manera pública su lectura de otros novelistas, ya sea estudiándolos, escribiendo sobre ellos o explicándolos en universidades, como Mario Vargas Llosa, quien, de este modo, en los últimos cuarenta años ha ejercido una formidable pedagogía de la novela en la doble vertiente que a él mismo más le importa: la novela como testimonio del mundo; la novela como forma perfecta, cerrada, orgánica, total.

Antonio Muñoz Molina (Jaén, España, 1956). Escritor y desde 1996 académico de número de la Real Academia Española. Estudió historia del arte en la Universidad de Granada y periodismo en Madrid. Dirigió el Instituto Cervantes en Nueva York hasta mediados de 2006. Autor de las novelas Beatus ille (1986), El invierno en Lisboa (Premio Nacional de Narrativa y Premio de la Crítica en 1987), Beltenebros (1989), El jinete polaco (Premio Planeta en 1991 y Premio Nacional de Narrativa en 1992). Los misterios de Madrid (1992, publicada inicialmente como serial a capítulos en el diario El País). En el otoño de 2009 se publica su novela La noche de los tiempos (Seix Barral), que recrea el hundimiento de la Segunda República y el inicio de la guerra civil española. Actualmente vive en Madrid y Nueva York. Amunozmolina@gmail.com. 
$\mathrm{N}$.

hay lector de novelas menos desinteresado que un novelista. Y por muy hondamente que un novelista escriba sobre otro estará escribiendo sobre sí mismo. Escribir versos puede hacerlo casi cualquiera que haya escuchado algunas canciones, aunque no haya leído mucha poesía. La poesía, tan cercana a la canción, es un arte que favorece el espontaneísmo, casi siempre con resultados catastróficos. Pero nadie se pone a escribir espontáneamente novelas: uno solo empieza a imaginar la posibilidad de intentarlo cuando ya ha leído muchas novelas, cuando se ha empapado de un género que por su propia naturaleza exige prolongadas inmersiones. En las novelas se vive. Se vive durante unas horas en el interior de una novela corta, durante días o semanas en otra más extensa, durante meses en los ciclos novelescos mayores, $A$ la recherche, La montaña mágica, los Episodios nacionales, La comedia humana. Una novela es una forma de vivir. Puede ser tan hospitalaria y protectora como una casa o una habitación y tan ilimitada como un país, como un continente. Puede que en la poesía exista eso que llamó Harold Bloom la ansiedad de la influencia: de lo que estoy seguro es de que en la novela abunda más el entusiasmo de la gratitud. Un novelista sabe que si ha llegado a serlo es gracias al ejemplo de otros novelistas. Un novelista solo aprende su oficio leyendo muchas novelas. Pero entre todas ellas hay siempre alguna sin la cual su vocación nunca habría existido; entre todos los novelistas hay uno que le hizo desear serlo.

Jules Verne fue el primer novelista del que yo tuve conciencia; el que me hizo descubrir que las novelas no existían de la misma manera primordial que los animales o los árboles, sino que habían sido inventadas y escritas por alguien. Leyendo a Verne decidí que yo también quería escribir novelas, con la misma determinación insensata con que don Quijote decidió que quería ser caballero andante, aunque con consecuencias menos desastrosas. Unos diez años después, cuando tenía veinte o veintiuno y llevaba muchas novelas leídas, hice otro descubrimiento: que las novelas no se escribían impremeditadamente, en raptos de inspiración o de capricho; que escribirlas era un trabajo marcado por la disciplina y el esfuerzo, quizás también por el sufrimiento. Eso lo 
descubrí leyendo La orgía perpetua. En sus páginas Mario Vargas Llosa contaba que él se hizo novelista leyendo Madame Bovary. A mí me sucedió eso leyendo este libro de Vargas Llosa sobre Flaubert y Madame Bovary. Jules Verne había sido el modelo de escritor de mi primera adolescencia: Flaubert, visto a través de Vargas Llosa, fue el modelo de mi juventud, el ejemplo que quise seguir cuando por fin emprendí la escritura de una novela.

Un novelista no lee con tranquilidad a otro novelista, y rara vez lo leerá con verdadera objetividad, especialmente si es contemporáneo suyo. Un novelista lee a otro para saquearlo. Tiene un instinto animal para saber lo que podrá aprovecharle y dejar de lado lo que no le nutre, como un ladrón que asalta una casa y aunque lo desordena todo solo se lleva las pocas cosas que le parecen de valor. Hay novelistas que lo que aprenden de otros lo aprenden de soslayo: mezquinamente no quieren dejar huellas de admiración, porque admirar implica reconocer en otro una grandeza que uno mismo no posee. Todo novelista es un lector de novelas, pero son muy pocos los que tienen el valor o la generosidad de admirar abiertamente, de hacer pública su lectura. Philip Roth lo hizo en Reading Myself and Others, en Talking Shop. Lo ha hecho también J. M. Coetzee. En nuestro idioma ningún novelista ha puesto tanto empeño en hacer pública su lectura de otros novelistas como Mario Vargas Llosa. Leyendo novelas con ahínco desde que era casi niño encontró su destino de novelista. Estudiándolas, sumergiéndose en ellas, escribiendo sobre ellas, explicándolas en las universidades, Mario Vargas Llosa ha ejercido desde hace más de cuarenta años un proselitismo formidable de la literatura, una pedagogía de la novela en la doble vertiente que a él mismo le importa tanto, le importa más: la novela como testimonio del mundo; la novela como forma perfecta, cerrada, orgánica, total. Alguien debería hacer la cuenta de todas las novelas sobre las que Vargas Llosa ha escrito, ha llamado la atención, de las que ha prologado, de las que ha vindicado. En ese aspecto su ambición generosa de lector solo se puede comparar en nuestro idioma a la de Octavio Paz. Qué otro novelista joven le dedicaría a otro de su misma generación un libro entero como el que él dedicó a Gabriel García Márquez. 
Pero Vargas Llosa, lector generoso, no es un lector desinteresado. Nadie que escriba novelas se puede permitir ese lujo. Hay demasiado que aprender siempre, demasiado territorio que cubrir, demasiada distancia entre los logros de casi cualquiera y la estatura de los grandes modelos con los que fatalmente seremos medidos. Cada gran novela es un mundo completo y hay tantas de ellas que su abundancia se parece a la posibilidad estadística de los mundos habitados en el universo. Un ensayo de Mario Vargas Llosa sobre otro novelista tiene siempre algo de manifiesto y declaración de principios. Que uno esté o no de acuerdo en sus juicios importa mucho menos que el ejemplo de la devoción con que él se consagra a escribir sobre otros. En las primeras páginas de $L a$ orgía perpetua se describe a sí mismo como un lector fanático, encerrado en una habitación de hotel con Madame Bovary, recién llegado a París y sin salir a la calle para aprovechar mejor el tiempo, para entregarse con una pasión del todo sensual a la lectura, al encuentro con esa mujer fantasmal y carnal que lo hechiza como Dulcinea del Toboso a don Quijote. Regresar a ese comienzo ahora, tantos años después de su primera publicación, de mi primera lectura, es acordarme de mí mismo en habitaciones semejantes, en habitaciones alquiladas tan escasas de comodidades como llenas de libros. Vargas Llosa no solo le enseñaba a uno cosas sobre las novelas, sobre la vida de Flaubert: también lo inducía a una determinada forma de lectura, a una especie de monacato alucinado en el que las palabras escritas y los personajes inventados tenían más consistencia que la borrosa realidad. Antes de leer Madame Bovary yo había leído varias veces La orgía perpetua, en aquella inolvidable edición de Seix-Barral, que era la editorial que a uno más le gustaba precisamente porque en ella estaban las novelas de Vargas Llosa. Antes de La orgía perpetua yo había leído ya La ciudad y los perros, La casa verde, Conversación en La Catedral. Gracias a eso comprendí en seguida que Vargas Llosa, escribiendo sobre Madame Bovary, estaba escribiendo sobre su propia poética como novelista, reivindicando un cierto modelo de novela y, sobre todo, un cierto modelo de escritor. Cualquier idea que uno hubiera alimentado sobre el genio inconsciente, sobre los arrebatos caprichosos de la imaginación, sobre la mala vida y el desorden como acicates naturales de la literatura, quedaba cancelada. No 
había que ser Julio Verne, ni Arthur Rimbaud, ni Jim Morrison, ni Jimi Hendrix, visionarios consumidos por el fuego mismo de su desmesura. Había que ser Gustave Flaubert.

No resultaba menos inalcanzable ser Mario Vargas Llosa. En 1975, cuando se publicó La orgía perpetua, Vargas Llosa no había cumplido ni cuarenta años y ya tenía tras de sí una secuencia de novelas fulgurantes, en un crescendo de fecundidad inventiva en el que quedaban como codas nada menos que Pantaleón y las visitadoras y La tía Julia y el escribidor. Nada menos. Escribir La orgía perpetua era una forma de hacer balance y de tomar aliento. Supongo que el impulso primero, como ocurre tantas veces, sería accidental, la solicitud de un prólogo para la nueva traducción de Madame Bovary que había hecho Miguel Salabert por encargo de Alianza. El Vargas Llosa de mediados de los setenta se tomaba una pausa después de más de una década de escritura infatigable en la que había pasado del anonimato a la cima de la novela latinoamericana y miraba atrás para encontrarse con el hombre joven que había sido más de veinte años atrás, el artista cachorro, el aprendiz de escritor, el recién llegado a Europa, el periférico que tiene la insolencia y el coraje de reclamar como suyo lo más canónico de la tradición de la metrópoli. En los años cincuenta, en París, leyendo Madame Bovary en una mezquina habitación de hotel para extranjeros insolventes, Vargas Llosa no solo estaba queriendo aprender el oficio de escribir novelas. Estaba también atreviéndose a usurpar lo que de acuerdo con los cánones no le pertenecía, la gloria de la novela europea y de la novela francesa; estaba negándose al destino melancólico de novelista colonial, de escritor confinado en el pintoresquismo de lo vernáculo peruano o latinoamericano. Borges había actuado con la misma desenvoltura al apropiarse sin apuro desde Buenos Aires de la entera tradición intelectual y literaria europea, con una mezcla desconcertante de reverencia y de burla. Hacia los mismos años en que Mario Vargas Llosa viajaba por primera vez a Madrid y a París, V. S. Naipaul abandonaba su isla de Trinidad para instalarse en Oxford con una beca, y Derek Walcott se marchaba de su mínima Santa Lucía caribeña para reclamar como suya la Itaca de Homero y toda la tradición más bien postergada de la 
gran poesía narrativa europea. A los hijos fugitivos de la periferia les corresponde la tarea paradójica de devolver la vida a las tradiciones demasiado solemnes de las culturas centrales: Borges nos devolvió a los españoles la gran fantasía literaria del Quijote, sepultada en nuestro país bajo capas de escombros de misticismo nacional; en la anémica literatura inglesa de los años cincuenta V. S. Naipaul recobró con A House for Mr. Biswas el gran caudal cómico y realista de Dickens; en su cuarto de meteco en París, en los años letárgicos del nouveau roman y del intelectualismo terminal francés, Mario Vargas Llosa erigió el ejemplo de Madame Bovary. Parecía que la novela se había quedado exhausta y que después de más de un siglo ya no le quedaba nada que contar y de pronto aquellos sudamericanos demostraban que el mundo estaba lleno de historias, que la vida contemporánea podía ser tan materia de la literatura como las provincias burguesas de mediados del XIX. Flaubert, en Madame Bovary, había hecho una novela con los materiales más vulgares de la realidad, con el melodrama de una señora cursi que lee novelas sentimentales y no quiere a su marido y se enamora de un par de sinvergüenzas. Y a partir de una historia así había construido un mecanismo perfecto, una forma tan pura, tan autosuficiente, tan hecha de estilo, armonía, ritmo, como un poema. La novela, la antigua máquina de contar, de pronto era más poderosa, más abarcadora que nunca.

\section{6}

Es raro volver, al cabo de los años, a un libro que a uno le ha importado mucho; que sigue estando tan presente en su conciencia que no siente la necesidad de leerlo de nuevo. A mí me ocurre eso con $E l$ Aleph, con El Astillero, con Heart of Darkness, con La orgía perpetua. La memoria es un editor tramposo: suprime, corrige, añade, transforma. Leí de nuevo hace poco dos de los cuentos que más me han impresionado en mi vida, The Tell-Tale Heart de Poe y The Swimmer, de John Cheever, y de los dos me sorprendió que eran mucho más cortos de lo que yo recordaba, mucho más despojados y más sintéticos. La memoria les había agregado duraciones y detalles. Vuelvo a La orgía perpetua para escribir estos apuntes y compruebo que mi recuerdo era muy exacto: los fragmentos desmelenados de la Correspondencia, la obsesión maníaca de Flaubert por los detalles, el tormento de escribir 
y escribir sentado en una silla, día tras día, año tras año, con una paciencia exasperada, no muy lejana de la locura. Así era como tenía que ser un escritor. Así se escribían las novelas, dejándose la vida en ellas, renunciando al mundo, esperando una recompensa que probablemente no llegaría, y que en cualquier caso nunca estaría a la altura de todo el trabajo y todo el sufrimiento concentrados en el libro. La orgía perpetua de escribir y leer era también un suplicio perpetuo. En construir la maquinaria meticulosa de una novela era preciso estar dispuesto a dejarse la vida. Cada frase, cada página, cada capítulo, era una lenta proeza. Un día entero podía dedicarse a completar una sola frase, una línea de diálogo. Era sin duda aterrador, pero también era heroico. La prueba de que esa disciplina constituía el único camino posible estaba en Madame Bovary y también en cada una de las novelas de Vargas Llosa que reverenciaba entonces cualquier aprendiz de novelista. Escribir no era una distracción, un capricho, una especie de aventura juvenil. Escribir era un empeño tan riguroso como ingresar en una orden monástica. Escribir era estar dispuesto a dejarse la vida. Qué miedo, qué tentación romántica. Madame Bovary era un manual para novelistas tan exigente como lo era todavía entonces, en aquella España del final de la dictadura, el Manifiesto Comunista. No era una lectura: era la sobria proposición de un compromiso en el que no había vuelta atrás.

\section{7}

También estaba muy claro lo que tenía que ser una novela: un mecanismo controlado al límite; una forma inflexible en la que no quedaba lugar para la improvisación o el desorden, una construcción impersonal que se basta a sí misma y se sostiene sobre sus propias reglas estructurales. Para un joven novelista esa exigencia de rigor es un aprendizaje valioso, porque actúa como correctivo de la autoindulgencia, del arrebato confesional, de la tentación narcisista, inevitable a esas edades. La tercera persona y el estilo indirecto libre aseguran el equilibrio justo entre distanciamiento e interioridad. La atención a la realidad material y al habla común son antídotos del amaneramiento en el estilo. Ningún logro llega por casualidad, o por milagro: todo es el resultado de un trabajo perpetuo, de una exigencia sin alivio. Para escribir una novela hay que estar dispuesto a pasar encerrado cuatro años y 
siete meses, a perder la salud, a no tener familia ni lazos sentimentales profundos. No es que haya que aspirar a ser Flaubert: es que no hay más remedio que serlo.

\section{8}

Las cosas, claro, no son tan radicales, ni tan indudables. Una gran novela se puede escribir a lo largo de cinco años y también en el arrebato de unos pocos meses. Una forma demasiado inflexible puede ser tan rígida que no permita la respiración de la vida, su azar, su desorden. Y para escribir novelas no siempre es necesario, o ni siquiera conveniente, aislarse hurañamente del mundo. La novela y la vida se alimentan mutuamente, en un flujo y reflujo que tienen el ritmo de las tareas cotidianas. Y quizás será deseable un término medio entre el novelista ermitaño y el novelista estrella, o procónsul, o personaje público, o emisario de sí mismo, condenado al tedio pomposo de las ceremonias, los viajes, los discursos sobre vaguedades prestigiosas, la frecuentación de prebostes políticos sin ningún interés.

Queda, desde luego, una lección que estaba en La orgía perpetua y que no puede olvidarse nunca: escribir, leer, son actos solitarios que se alimentan de sí mismos y que tienen en ellos mismos su mejor recompensa. Tantos años después, cada vez que me pongo a escribir una novela o a leerla vuelvo a la habitación en la que me enseñaron a encerrarme Gustave Flaubert y Mario Vargas Llosa. Sigue durando la orgía perpetua de la literatura. 